\title{
Forecasts of urbanization scenarios reveal trade-offs between landscape change and ecosystem services
}

\author{
Brian R. Pickard · Derek Van Berkel · Anna Petrasova $\cdot$ Ross K. Meentemeyer
}

Received: 8 February 2016/Accepted: 8 November 2016/Published online: 17 November 2016

(C) The Author(s) 2016. This article is published with open access at Springerlink.com

\begin{abstract}
Context Expansion of urban settlements has caused observed declines in ecosystem services (ES) globally, further stressing the need for informed urban development and policies. Incorporating ES concepts into the decision making process has been shown to support resilient and functional ecosystems. Coupling land change and ES models allows for insights into the impacts and anticipated trade-offs of specific policy decisions. The spatial configuration of urbanization likely influences the delivery and production of ES.

Objective When considering multiple ES simultaneously, improving the production of one ecosystem service often results in the decrease in the provision of other ES, giving rise to trade-offs. We examine the
\end{abstract}

Electronic supplementary material The online version of this article (doi:10.1007/s10980-016-0465-8) contains supplementary material, which is available to authorized users.

B. R. Pickard ( $\square)$ · D. Van Berkel · R. K. Meentemeyer Department of Forestry and Environmental Resources, North Carolina State University, 2820 Faucette Dr., Campus Box 8001, Raleigh, NC 27695, USA

e-mail: brpickar@ncsu.edu

\section{A. Petrasova}

Department of Marine, Earth, and Atmospheric Sciences, North Carolina State University, Raleigh, NC, USA

B. R. Pickard · D. Van Berkel · A. Petrasova .

R. K. Meentemeyer

Center for Geospatial Analytics, North Carolina State

University, Raleigh, NC, USA impact of three urban growth scenarios on several ES to determine the degree to which spatial configuration of urbanization and the development of natural land cover impacts these services over 25 years.

Methods We couple land change and ES models to examine impacts to carbon sequestration, surface water-run off, nitrogen and phosphorus export, organic farming and camping site suitability, to determine trade-offs among the six ES associated with each spatial configuration for western North Carolina.

Results Consequences of urban configurations are dramatic, with degraded ES across all scenarios and substantial variation depending on urban pattern, revealing trade-offs. Counter-intuitive trade-offs between carbon sequestration and lands available for organic farming and camping were observed, suggesting that no configurations result in mutual benefits for all ES.

Conclusions By understanding trade-offs associated with urban configurations, decision makers can identify ES critical to an area and promote configurations that enhance those.

Keywords Ecosystem services · Trade-offs · Land change $\cdot$ Geospatial

\section{Introduction}

Increasing world population has resulted in the conversion of natural landscapes to urban land use, 
globally altering the relationship between humans and the natural environment. The goods and services provided by ecosystems to society, frequently referred to as ecosystem services (ES), are increasingly under pressure as urban settlements continue to expand (Millennium Ecosystem Assessment (MEA) 2005). Urban sprawl can be defined as the spreading of an urban area and its suburbs over rural land at the outer periphery of an existing development in an often disjunct, or "leap frog" pattern (Downs 1999; Kaza 2013). Within the United States, urban sprawl is a dominant development pattern driven by population and unfettered land use planning (Hamidi and Ewing 2014) that has caused increases in impervious land cover and density over the past decade (Homer et al. 2015). Alternative growth strategies, sometimes referred to as "green growth" or "sustainable growth", have emerged as possible solutions to sprawl. Green growth strategies, such as infilling new development near existing urban areas, can potentially reduce service costs (Carruthers and Ulfarsson 2003) and emissions from vehicles (US Environmental Protection Agency 2001), protect ecological systems and may conserve forests and farmlands by reducing disjunct development (Meentemeyer et al. 2013). However, it is unclear how alternative spatial configurations of urban development that shape mosaics of land cover around urban areas will impact the delivery of environmental goods (Eigenbrod et al. 2011; Nedkov and Burkhard 2012). With global populations projected to increase, it is critical to understand the relationship between expanding urban configuration and ES in different geographic context to identify specific trade-offs.

Patterns of land cover and use has been extensively investigated in ES studies. Less understood is how alternative urban configuration might impact the services important to urban residents within the same or similar context. One option for investigating these relationships is coupling ES models with simulations of different alternative developments using land change models (e.g. Nelson et al. 2009; Renard et al. 2015; Tayyebi et al. 2015). By offering scenarios of land change, these types of studies can offer policy relevant insights into how different landscape configurations impact ES delivery. High profile international and state efforts have recently called for integrating ecosystem service models into land-use decision making (Global Land Project, Intergovernmental
Panel on Biodiversity and ES), recognizing that the coupled ES and land change modeling approach can enhance policy design. This was first articulated in 2005 with the Millennium Ecosystem Assessment (MEA 2005), highlighting that an estimated $40 \%$ of ecosystem services were in a state of decline primarily due to urbanization.

Despite numerous land change models that include urban transitions [e.g. CLUE: Verburg and Overmars (2009), SLEUTH: Clark et al. (1997), and UrbanSim: Waddell (2002)], few studies have coupled projected land change with ES evaluation in highly urbanizing areas (Eigenbrod et al. 2011; Nedkov and Burkhard 2012). The notable exception of Eigenbrod et al. (2011) found that densification of urban growth results in higher peak flows but minimizes losses of stored carbon and agricultural production compared to suburban sprawl. However, further study is needed to assess the generalizability of these result for better understanding urban patterns influence on ES. Assessment of ES requires spatial resolutions and extents that represent the ecological processes at which ES are delivered and simulating patterns representative of actual urban configuration. A continuing challenge for land change models such as CLUE (Verburg and Overmars 2009), SLEUTH (Clark et al. 1997), and UrbanSim (Waddell 2002), is simulating patterns at large extents with the resolution needed to assess fine scale ES processes. Often coarser scale analysis is used due to computational requirements (Eigenbrod et al. 2011), yet there still remains a need to anticipate urban pattern and form in more spatially explicit and accurate ways.

Evaluation of multiple ES has led to the recognition that the improvement of some services can occur at the detriment of others (e.g. Nelson et al. 2009; Eigenbrod et al. 2011; Renard et al. 2015). By illuminating these types of trade-offs due to urban configuration, decision makers are able to weigh efficient use of resources for strategies that increase resilience and sustainability (Schaefer et al. 2015). The results of Howe et al. (2014) systematic literature review, for instance, found a relatively small number of ES studies between 2003 and 2013 that recorded actual or potential tradeoffs $(n=231)$. Moreover, there are fewer studies that address urban areas and the suite of services applicable to urban populations, focusing on typically only one service of provisioning as opposed to non-provisioning services (e.g. cultural ES) (Ziter 2015). Much 
focus has been placed on trade-offs associated with habitat diversity (Maskell et al. 2013) or landscape complexity (Laterra et al. 2012), with few studies addressing landscape configuration and temporal dynamics (Liu et al. 2012). Recent studies that considered temporal dynamics using land change modeling (Costanza et al. 2014; Schaefer et al. 2015; Lawler et al. 2015) have been of a resolution that is difficult to translate results to urban policymakers. The lack of studies investigating the manipulation of specific spatial configurations of individual land cover types (e.g. urban) and the corresponding conversion of other land cover types to that configuration remains a research gap.

In this paper we examine the impact of urban growth scenarios including maintaining historical trajectories of urban growth, sprawl and a green growth strategy that specifically infills new development, over 25 years, on several ES to determine the degree to which the spatial configuration of urbanization impacts these services. We couple a land change model (FUTURES; Meentemeyer et al. 2013) with ES models to: (i) simulate plausible spatial configurations of sprawl, infill and maintaining the status quo, (ii) determine how this impacts carbon sequestration, surface water-run off, nitrogen and phosphorus export, organic farming and camping site suitability, and (iii) identify the trade-offs among the six ES associated with each spatial configuration. FUTURES is a multilevel urban model framework that simulates land change patterns typically observed with development in the US, making it a desirable choice for understanding urban growth patterns impacts to ES. Our aim is to demonstrate the importance of spatial location and configuration of urbanization in addition to total urban growth. By manipulating urban growth patterns of sprawl or infill that occurs, we highlight vastly different trade-offs in ES provisioning that can occur at landscape scales. Elucidating ES trade-offs associated with urban form can inform and guide landscapescale planning to promote sustainable environmental solutions and resiliency.

\section{Study region: Western North Carolina}

The study extent (Fig. 1a), referred to as the Western North Carolina region, includes portions of the Blue Ridge Mountains and Piedmont plateau physiographic regions. The Blue Ridge Mountains are characterized as mountainous with elevations exceeding 6000 feet $(1800 \mathrm{~m})$. Comparatively, the Piedmont Plateau region consists of relatively low, rolling hills with elevations ranging from 200 feet $(50 \mathrm{~m})$ to 1000 feet $(300 \mathrm{~m})$. These two physiographic regions create highly suitable areas for urban development, but are constrained by topography. Urban settlements are typically found lower in the valleys near the foothills of the Blue Ridge Mountains and development is constrained by the steep mountain terrain. The region also hosts a number of endangered or threatened species, diverse aquatic resources, cultural and historical heritage areas, and a vibrant outdoor tourism industry. In 1976, 0.7\% of the region was developed: in 2006 developed lands had increased to $4.8 \%$ (Fig. 1a) and are projected to increase to $7.9 \%$ by 2035.

According to the North Carolina Office of State Budget and Management, the population in the 19 county region of Western North Carolina increased $42 \%$ between 1976 and 2006, from 545,000 to 774,281 people, respectively. The region's population is projected to increase by an additional $19.2 \%$ in the next two decades (NCOSBM 2012). There are very few major urban centers, the largest being Asheville, North Carolina (Fig. 1b). The greater four county Asheville Metropolitan Statistical Area (MSA; Fig. 1a) have experienced rapid unplanned expansion, with the MSA experiencing $14.6 \%$ population growth in the last decade (NCOSBM 2012). Compared to the population in 2000, the MSA population is projected to increase by an additional $26.2 \%$ by 2035 (NCOSBM 2012). These growth projections combined with the regions multiple land uses and natural resources make the transitional terrain between the Appalachians and the Piedmont Plateau an ideal study location to investigate the trade-offs associated with scenarios of differing urban configuration.

\section{Materials and methods}

ES science has largely focused on understanding the relationship between land cover and ecosystem properties and quantification of service for evaluating the benefit from ecological systems (De Groot et al. 2010). Research to date has generally neglected addressing the spatio-temporal dynamics of land change and ecosystem service response from specific urban 


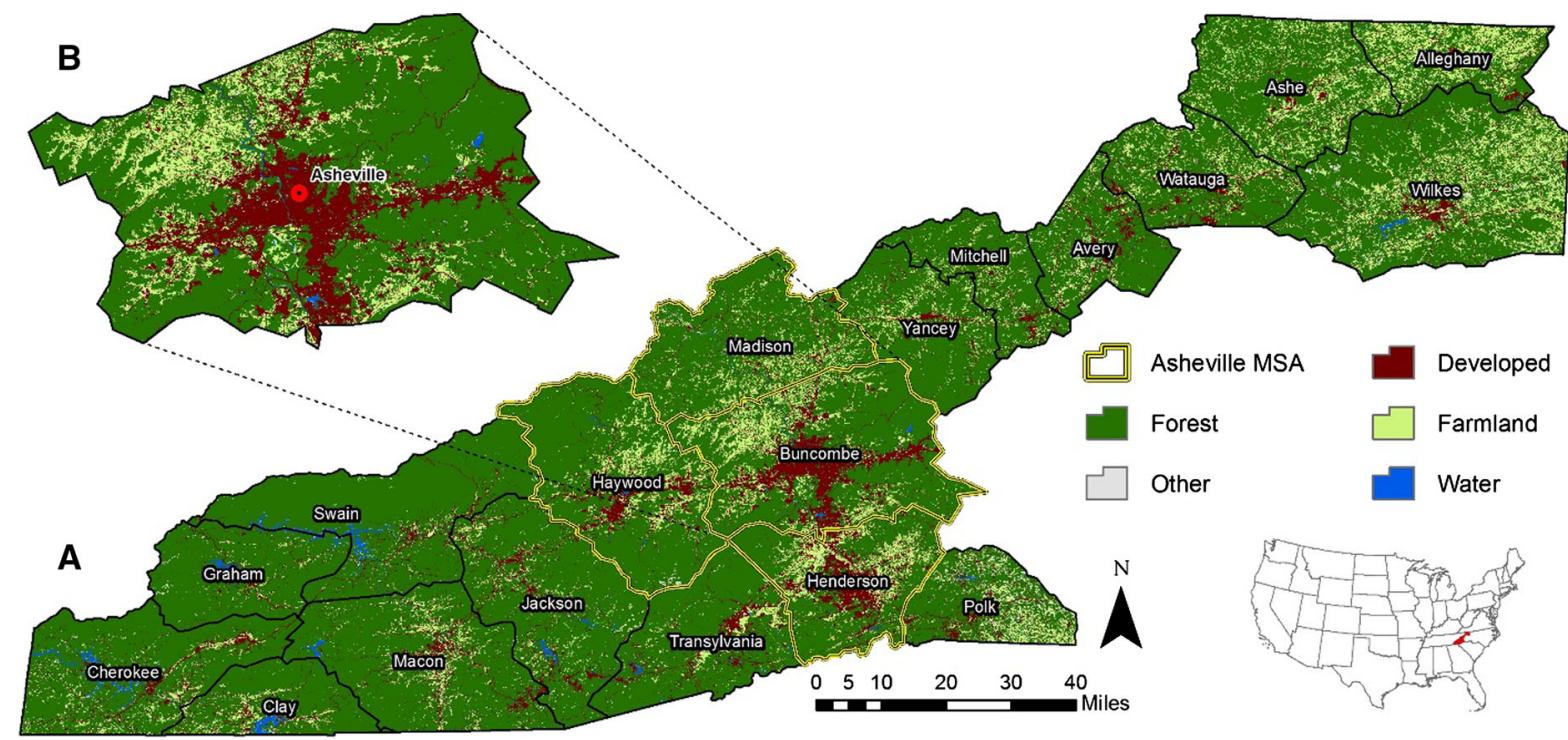

Fig. 1 The western North Carolina region a used as the study extent includes nineteen counties with a diverse mix of developed and undeveloped land use types with one metropolitan statistical area located in Asheville, NC. b Buncombe

growth configurations at spatially explicit and relevant resolutions. We contribute a novel methods to understanding how changing the spatial configuration of urban form, and the corresponding conversion of land cover types to urban, will impact a suite of ES in space and through time.

Land change model

To investigate scenarios of urban growth strategies, we simulated land change for 19 counties in the Western North Carolina region from 1995 to 2030 using the FUTure Urban-Regional Environmental Simulation (FUTURES) model (Meentemeyer et al. 2013), specifically its open source model developed by Petrasova et al. (2016). FUTURES is a multi-level modeling framework that projects the emergence of impervious urban configuration using a stochastic region-growing algorithm and site suitability. Unlike many land use models designed to simulate land change [e.g. CLUE: Verburg and Overmars (2009), SLEUTH: Clark et al. (1997), and UrbanSim: Waddell (2002)] FUTURES offers the ability to simulate realistic patterns of growth relevant to land changes that likely influence ES relevant to urban residents in the US. Realistic patterns of urban growth are simulated based on past observed patterns at the
County (used for FUTURES patch calibration) depicts a typical urban to rural gradient with growth rates and urban patterns representative of the entire western North Carolina region

individual pixel level. FUTURES estimates urbanization as impervious surface and does not consider other land cover conversions. Simulated maps of urban land cover were compared with current land use maps to evaluate different land use conversion rates.

\section{FUTURES sub-models}

FUTURES consist of three sub-models that drive estimates of the magnitudes and configuration of urbanization. A DEMAND sub-model determines the quantity of land converted to urban based on projected population increase and per capita land consumption, the POTENTIAL sub-model identifies locations of potential urban development based on site suitability, and a patch growing algorithm sub-model (PGA model) simulates observed spatial configurations using an iterative, stochastic site selection process and a discrete patch-based region growing algorithm (Meentemeyer et al. 2013). Scenarios of different urban growth strategies are simulated by varying land consumption (population density per pixel), and shifting the importance of proximity to existing urban land for development in the POTENTIAL sub-model. Status quo, infill and sprawl scenarios were run 30 times for our study system to account for model stochasticity, as development that occurs in each run 
will be different due to the site selection process described below.

Land demand was calculated using estimates of trends in population growth and land consumption for each of the 19 counties separately. Land consumption was derived from classification of urban land change using Landsat imagery for 1976, 1985, 1996, and 2006 time steps. Classification of the four time steps was based on the vegetation-impervious surface-soil (VIS) model (Ridd 1995) and normalized spectral mixture analysis (Wu 2004). Classification accuracy for the 1976 image was $75 \%$, for 1985 approximately $87 \%$, and for 1996 and 2006 approximately 84\%. For each county, linear regression was used to identify the relationship between total land developed and observed population changes. Using future population estimates provided by the North Carolina Office of State Budget and Management, we projected the total land expected to be developed for each county based on the derived empirical relationship of land use and population observed from 1976 to 2006 . This method of land demand extrapolation assumes a generalized trend of population growth based on approximately 40 years of observed growth-while FUTURES is able to account for scenarios involving policy or economic events such as market failures or the US housing collapse of 2008 , we chose to add no such acute event within our projected period.

We used a linear mixed-effects model to determine the relationship between undeveloped lands converted to urban based on environmental and socio-economic conditions following Meentemeyer et al. (2013). Principal component analysis was used to select a set of key indicators explaining locations of urban growth (Table S1). Model parameters were estimated based on the binary response (land converted or not) for approximately 16,500 randomly sampled points. To account for variability between counties not captured by selected indicator variables that likely influenced urbanization, random effects were assigned to the intercept and development pressure variables. The development pressure random effect accounts for unexplained development factors that likely influence development but were not chosen (e.g. taxes, school district, or zoning). The intercept random effect accounts for the variance of each counties initial development unexplained by the predictor variables.

Estimates were incorporated in the POTENTIAL sub-model for simulating accurate development based on site-suitability. We used size and shape of newly developed patches between the reference years to parameterize the PGA simulating past development configurations for the projected years. At the individual cell level, the PGA stochastically allocates seeds to grow a patch chosen randomly from the distribution of patch sizes within a "patch library". The patch library is a distribution of patch sizes that is derived from observed patches of new development from 1995 to 2006. The PGA uses two parameters, patch size and compactness, to influence a patch shape to be similar to observed patches. Optimal parameters are selected by running the FUTURES simulation using a range of parameter values, and selecting the best match by comparing the Chi square distance (Belongie et al. 2002) of the histograms of simulated patches and observed patches in the reference period. The simulated runs were repeated ten times for each parameter value to account for the stochasticity of the FUTURES model. Calibration is a computationally extensive process, therefore we calibrated patches for Buncombe County due to the extensive new development that occurred during the reference period, and used these parameters in the PGA for the simulations of the complete study area.

An urban patch is "successfully developed" based on an algorithm that stochastically choses a location on the landscape, compares the selected location with a map describing the probability of future development occurring at that site (i.e. the POTENTIAL submodel), and a Monte Carlo challenge that must exceed the probability value of the location. If the location successfully survives the Monte Carlo challenge, a discrete patch is then selected from the patch library and allocated on the landscape. This process occurs iteratively, developing patches until the total number of new cells for the simulation year are allocated (determined by the DEMAND sub-model). Once the land demand is met for the year, the development pressure indicator variable and the POTENTIAL surface are updated prior to restarting the simulation for the next year. This patch growing process repeats until the final year of simulation is completed. We chose to hold constant the total amount of land developed across all scenarios, and only manipulate the configuration of urban growth to understand the impact to ES. Prior to running the model, protected lands (e.g., National and State parks, National Forests, Bureau of Land Management etc.) within the State 
were masked to restrict development from occurring within their boundaries.

We validated FUTURES model performance by comparing simulated urbanization from 1992 to 2006 to observed change in the National Land Cover Data (Fry et al. 2011). The percentage of cells that correctly converted from natural land cover types to urban was determined for all 30 simulation runs using the status quo scenario. Overall accuracy of FUTURES to correctly predict the exact cell location of new development (locational accuracy) during this time period was approximately $21.1 \%$ (standard deviation $0.4 \%$ ). These results are consistent, and generally improve on, locational accuracy reported in other LULC modeling studies (Pontius et al. 2008). The systematic review of several LULC models (e.g. CLUE, SLEUTH, GENMOD, Land Use Scanner) by Pontius et al. (2008) found that model performance to project individual cell locations typically were less than $10 \%$. The authors explain that pixel-level validation methods ignore near and far misses, but may still accurately simulate urban spatial configurations consistent with observed growth (Verburg et al. 2002).

\section{Scenarios of urbanization}

To better identify trade-offs among ES due to expanding urban areas, modeling urbanization at the two extremes of the spatial configuration spectrum (i.e. rapid sprawl and infill new growth) is needed. It is likely that most urban growth occurs somewhere in the middle of this spectrum, with some configurations working better than others in different locations (Chaplin-Kramer et al. 2015). Therefore, it is imperative to understand how changing urban form can impact ES, and if optimal configurations at landscape scales may be achieved (Polasky et al. 2008). Employing systematic simulations of alternative urban growth configurations can add insight into how different growth strategies influence the environment and the services around urban areas. By integrating pattern, extent, and intensity of urban configuration into ES science, it may be possible to promote important ES conservation objectives through specific patterns of urban growth. Ultimately, this may allow for better informed land and resource management.
Maintaining status quo growth pattern FUTURES is calibrated based on the size, shape, and spatial configuration of urbanization for the identified reference period (1996-2006). Status quo development maintains the same model parameters for simulation year to 2030. We modeled a status quo growth scenario to provide context and to aid in understanding how spatial configurations of urban growth impact ecosystem services. Previous studies have used a status quo growth pattern scenario to serve as a benchmark for current urban planning (Gude et al. 2007; Beardsley et al. 2009; Meentemeyer et al. 2013; Dorning et al. 2015) as it can be useful to assess modified configurations relative to continuation of current trends.

Ecological conservation: infill New trends in urban development have centered on smart growth strategies aimed at reducing development pressure on outer lying areas and to help protect lands that provide essential ecosystem functions (United States Environmental Protection Agency 2014; Kahn 2006). Infill development clusters new growth near existing urban areas using different planning instruments (e.g. zoning). Infill was simulated using the incentive parameter within the PGA submodel to constrain the development potential surface in the POTENTIAL sub-model (Meentemeyer et al. 2013).

Rapid urbanizing sprawl Increasing urban sprawl has been identified as an environmental and economic challenge to sustainability (Jaeger and Schwick 2014). It has been attributed to losses of open landscapes and habitats for biodiversity, the spread of invasive species, and decreases in carbon pools (McDonald et al. 2008; Setto et al. 2012), and is now considered a prevailing attribute for many developed countries. Development, not necessarily in close proximity to existing urban areas, is often characterized by a disjunct, and "leap frog" pattern (Holcombe and Williams 2012). Sprawling growth was simulated using the incentive parameter within the PGA submodel to expand the development potential surface in the POTENTIAL sub-model (Meentemeyer et al. 2013), effectively creating an inversely related scenario to the infill strategy. 
Land change and ecosystem services model coupling

Land use/land cover is an important determinant of ES amongst other landscape characteristics (Seppelt et al. 2011). Six ES (carbon sequestration, surface water run-off, nutrient loading, organic farming and camping site suitability) were chosen for evaluation based on their importance for the region's economy and broader trends affecting societal preferences for amenity landscapes. We modeled each ecosystem service using the simulated land change outputs from FUTURES for each urban growth configuration at 2006 and 2030 to quantify the change in service. FUTURES determines spatial configuration of new development stochastically, therefore for each development scenario (status quo, infill, and sprawl) we quantified the change in service for each of the thirty individually run simulations and report an average. Our results represent general trends that could be observed from urban configuration, and not the results of a single stochastic simulation. By averaging many simulations for each model, we aimed to converge on general trends, rather than report possible variation that could arise from the stochasticity of the FUTURES model. All ecosystem service models were mapped at $30 \mathrm{~m}$ spatial resolution and all other model parameters were held constant. By holding the other parameters constant, we are able to quantify the change to each service as a direct result of the increase in urbanization and the specific spatial configuration of each urban growth scenario.

\section{Regulating ecosystem services}

Carbon Many land cover types, and in particular forest lands, play an important role in the global carbon cycle (Pan et al. 2011). To quantify the total amount of carbon stored and sequestered for aboveground biomass, soil and dead organic matter, we used the InVEST (Integrated Valuation of Ecosystem Services and Trade-offs) Carbon Storage and Sequestration Model (3.2.0) (Sharp et al. 2015). InVEST is a widely used suite of open source geospatial models, developed by the Natural Capital Project, designed to quantify different ecosystem services based on land cover and related environmental data. In the study, we used the carbon model to define carbon pools for each land cover class. Coefficients were derived from existing literature for each land cover type (Penman et al. 2003; IPCC 2006; Blumstein and Thompson 2015; Chaplin-Kramer et al. 2015). We estimated the change in carbon storage and sequestration based on changing land cover across scenarios. An estimate of the total carbon stored by mass of elemental carbon $(\mathrm{Mg})$ in each $30 \mathrm{~m}$ grid cell is given.

Inventory type models, such as the InVEST Carbon model, provides a simplified representation of carbon storage and sequestration based on the assumption that all land cover types have fixed carbon storage levels (Sharp et al. 2015). Such assumption ignores possible above- and below-ground level carbon variation, and local conditions that influence actual sequestration over time. While simplistic in methodology, such crude estimates provide effective means to investigate trends in changes to carbon sequestration directly resulting from increasing urbanization and its configuration.

Surface water run-off Land cover influences the amount of surface water that runs across the landscape (Blumstein and Thompson 2015) and is important in the urban context because it changes runoff patterns resulting in increased storm flow rates and volumes and corresponding reductions in base flow and volumes (Leopold 1968; Konrad and Booth 2005; Blumstein and Thompson 2015). We used the InVEST Water Yield model to quantify changes in surface water run-off (Sharp et al. 2015). The InVEST Water Yield model combines climate and soils data with the FUTURES land cover scenarios to calculate an aggregated water yield determined from flow paths of surface water run-off across the landscape (Sharp et al. 2015). Flow paths and the volume of surface water carried across the landscape is influenced by the spatial location of specific land cover types. Redhead et al. (2016) have shown that the InVEST Water Yield model to have a high degree of accuracy when projecting surface water runoff at landscape scales.

The InVEST Water Yield model requires data on the precipitation, average annual reference evapotranspiration, plant available water content, root restricting layer depth, a digital elevation model and land cover to parametrize annual surface-water runoff. Monthly precipitation and potential evapotranspiration data were obtained from PRISM Climate datasets for the years 1995-2006 (Daly et al. 2004; DiLuzio et al. 2008) and summarized to an annual average. Using a decadal 
annual average allows for the separation of inter-annual variability in precipitation and potential evapotranspiration. Plant available water content and root restricting layer depth were obtained from SSURGO soils data (SSURGO 2015) produced by the National Resources Conservation Service (NRCS). The digital elevation model was obtained from the National Elevation Dataset provided by the United States Geological Survey. The required landcover for this model was supplied as the output of each FUTURES model run. The spatial resolution of all data used for the InVEST Water Yield model was $30 \mathrm{~m}^{2}$.

\section{Provisioning ecosystem services}

Phosphorus and nitrogen export Eutrophication of freshwater resources and coastal ecosystems is caused by increases in nitrogen and phosphorus, and is a key issue for water quality in the Southeastern United States causing increased filtration costs and degraded water quality (Garcia et al. 2009). Different land cover types affect the quality of water resources by contributing varying amounts of nutrients, such as phosphorus and nitrogen, to surface and ground waters (Polasky et al. 2011) and may result in changes to filtration costs (Carpenter et al. 1998). Understanding how nutrients are exported across a landscape as a direct result of urban development is important for developing water management policy through land use planning.

We used the InVEST Nutrient Model 3.2.0 (Sharp et al. 2015) to quantify nitrogen and phosphorus export for each scenario. The nutrient retention model calculates hydrologic flow paths based on elevation and determines the amount of nutrients filtered by terrestrial vegetation. This process is iteratively run following an elevation gradient until a stream is reached. Accumulated nutrients from each pixel that are not filtered by land cover are amalgamated and exported to the stream. Model parameters were approximated from existing literature and calibrated using results from two Spatially Referenced Regression on Watershed models (Hoos and McMahon 2009; Garcia et al. 2009).

\section{Cultural ecosystem services}

Potentially suitable organic farming lands Expanding intensive mono-cropping, while being an important source of food, can also be detrimental to ecological systems, especially with regards to biodiversity (Pimentel et al. 1995; Tuck et al. 2014). Organic farming has emerged as an alternative to intensive agriculture (Mader et al. 2002) and has been shown to benefit the environment while still producing reasonable crop yields (Drinkwater et al. 1998; Reganold et al. 2001). Moreover, organic farming frequently results in landscape configurations that are appealing and valued societally (Junge et al. 2011).

To map and quantify prime organic farming lands we collected locations of known organic farms from the North Carolina Department of Agriculture and Consumer services website (www.ncfarmfresh.com/ farms.asp). Organic farming locations were mapped using coordinates derived from geocoding (Google API) and a database created with corresponding landscape characteristics likely influencing farm suitability for each location. Estimates of enhanced vegetation index (EVI) for August, average annual minimum temperature, irrigation potential, distance to potable water wells, agricultural suitability, percentage woodland, travel time to urban centers with populations exceeding 50,000 and population density were quantified for each organic farming location. For each landscape indicator, a $250 \mathrm{~m}$ neighborhood (50 acres) was used to derive an average value of the landscape variables around each organic farm. A logistic regression was fitted to investigate the influence of each landscape indicator and its contribution to the occurrence of organic farm locations (Table S2) (AUC: 0.79). We used a presence/absence sampling method that included all organic farm locations obtained $(n=2551)$ and a random sample of locations where no known organic farming has occurred $(\mathrm{n}=7653)$. Model estimates were used to calculate suitable locations for organic farms for the scenarios. The upper quartile of the logistic regression probability $(<0.75)$ was deemed a good threshold for describing locations appropriate for this farm type. Locations represent aesthetically appealing landscape characteristics locally associated with organic farm and soil quality necessary for such land use. Estimates of suitable organic farming were created for each urban growth scenario.

Camping site suitability The Asheville region is a well-known outdoor retreat in North Carolina, offering extensive leisure and recreation potential 
due to the beauty of the mountain topography and surrounding forested landscape. It is also an important economic driver in the region with approximately twenty-one billion dollars spent in North Carolina from tourists in 2013 alone (NC Division of Tourism 2014). With the Blue Ridge Mountains adjacent to the Asheville region, camping and backpacking are the predominant forms of recreation enjoyed within the study region.

A similar technique to that described in the organic farm evaluation was used to map and quantify suitable locations for camping across North Carolina. Addresses of camping sites were collected from Travel North Carolina, the State's official travel advertising website, and geocoded using the Google API (http://www.visitnc.com/). Again, a logistic regression model was fitted to landscape characteristics likely influencing camping site suitability (presence: 418; absences: 1254) (Table S3). The estimated model (AUC: 0.82) revealed the importance of amenities like lakes and river, protected areas, forest, topography and recreation attractions (e.g. hiking trails, local restaurants). Proximity to well water and average annual temp suggest that camping sites are located in valley bottoms. A site suitability of $(<0.75)$ was used as a threshold for the most suitable camping areas and modeled based on each urban growth strategy scenario.

\section{Results}

Simulated land change using FUTURES

Simulation of urbanization revealed highly different configurations of land use based on different urban growth strategies (Table 1). Figure 2 shows the different landscape configurations of the three scenarios and the initial 2006 conditions. The total amount of land converted to urban in each of the three scenarios was approximately the same, however under the infill scenario we observed a tight clustering of new urban patches placed near existing urban areas and the opposite for the sprawl scenario. When the status quo growth is maintained, new patches of urbanization occur in a similar manner to both the sprawl and infill scenarios simultaneously-a trend observed across the study region for the last decade.
Urbanization was projected to increase by approximately 24 percent across all three of the urban growth scenarios (Table 1). The modest differences (less than $0.6 \%$ ) in total hectares of development can be attributed to the final patch developed in each year of a simulation. The last patch chosen from the patch library for each year is allocated in its entirety, rather than divide the patch to meet the exact land demand for the given year. Therefore, slight differences in the amount allocated each year can occur, and are aggregated over the entire simulation time period. However, our results demonstrate that differing scenarios of maintaining the status quo, infilling and sprawling urban growth patterns will cause dramatic differences in the types of land cover classes converted to urban. When comparing the two urban growth strategies to the status quo scenario we found that conversion of land classes were inversely related to one another. However, the percent changes of each land cover class were not identical inverses of each other.

Maintaining the status quo resulted in modest decreases $(<8 \%)$ of barren, shrubland, grassland and wetland land cover for the 25 year reference period (Table 1). Approximately $3 \%$ of existing forest was lost to urban growth under this scenario (Fig. 3). While the conversion of forest land cover to urban was minimal, due to the heavily forested landscape, the $3 \%$ decrease resulted in approximately 46,452 ha on average across all thirty simulations (Table 1 ). The largest decrease $(10.7 \%)$ in land cover type was the conversion of planted and cultivated lands to urban, representing approximately 19,000 ha lost (Table 1).

Infilling urban growth near existing urban areas resulted in similar losses of barren land cover compared to the status quo. This scenario resulted in a greater loss of shrubland, grassland, and wetlands than maintaining the status quo. The additional losses of these land cover types compared to the status quo were small, representing less than 300 ha in aggregate (Table 1). Forested lands were conserved by approximately 6000 ha compared to the status quo scenario with only a $2.7 \%$ decrease (Fig. 3 ). However, with the conservation of forested lands an additional 3000 ha of planted and cultivated lands were lost to urbanization (Table 1). This represents a $12.5 \%$ loss of cultivated and planted lands, approximately $1.7 \%$ more than continuing status quo growth (Table 1). 
Table 1 Changes in land cover/land use from the three urban growth scenarios over 25 years (2006-2030)

\begin{tabular}{|c|c|c|c|c|c|c|}
\hline \multirow[t]{2}{*}{ Land cover/land use } & \multicolumn{2}{|l|}{ Status Quo } & \multicolumn{2}{|l|}{ Infill } & \multicolumn{2}{|l|}{ Sprawl } \\
\hline & \pm Hectares & $\%$ Change & \pm Hectares & $\%$ Change & \pm Hectares & $\%$ Change \\
\hline Urban & $68,346(60)^{\mathrm{a}}$ & 23.8 & $65,960(62)$ & 23.7 & $72,172(60)$ & 24.3 \\
\hline Barren & $-123(7)$ & -5.8 & $-124(7)$ & -5.8 & $-113(7)$ & -5.4 \\
\hline Forest & $-46,452(127)$ & -3.1 & $-40,930(149)$ & -2.7 & $-56,099(107)$ & -3.8 \\
\hline Shrubland & $-1078(14)$ & -5.1 & $-1138(19)$ & -5.4 & $-967(22)$ & -4.6 \\
\hline Grassland & $-1727(23)$ & -7.7 & $-1850(24)$ & -8.3 & $-1380(24)$ & -6.0 \\
\hline Planted/cultivated & $-18,802(107)$ & -10.7 & $-21,730(130)$ & -12.4 & $-13,500(102)$ & -7.5 \\
\hline Wetlands & $-155(7)$ & -6.3 & $-178(8)$ & -7.2 & $-105(7)$ & -4.2 \\
\hline
\end{tabular}

a Mean (SD)

Increased sprawl was inversely related to the infill strategy. Sprawling urban growth resulted in conservation of barren, shrubland, grassland, and wetlands compared to continuing growth as usual. Losses in forested lands were greater than the two other scenarios, with approximately 56,000 ha converted to urban land (Table 1). This loss was 10,000 ha greater than the status quo scenario, and 16,000 ha greater than the infill strategy (Table 1). Conversely, planted and cultivated lands were substantially conserved compared to the other two scenarios, resulting in only 13,500 ha being converted to urban (Table 1). An additional 5000 ha of these lands would be lost under the status quo, and a total of 8000 ha more would be lost from the infill strategy.

\section{Model coupling results}

\section{Carbon sequestration}

We observed a decrease in the amount of annual carbon sequestered across all three urban configuration scenarios due to the conversion of natural land cover types that are carbon sinks (Fig. 4a). The sprawl scenario resulted in the most significant decreases with a loss of approximately 10.8 million tons sequestered. The status quo and infill strategies decrease by 9.6 and 8.9 million tons, respectively (Fig. 4a). These estimates represent the annual change in sequestered carbon and are not aggregates of the 25 years modeled period.

\section{Surface water run-off}

Annual surface water run-off increased in each of the scenarios of urban growth (Fig. 4b). Increases of 68 megaliters of annual run-off were observed for the status quo scenario. The two urban configuration scenarios of sprawl and infill had increases of 76 and 63 megaliters respectively (Fig. 4b). This relatively low variability is likely the result of using average decadal precipitation data. It does not reflect other related surface water metrics attributed with increases in impervious surface such as flooding. Urban infill growth strategies will likely result in less surface water run-off throughout the year.

\section{Phosphorus and nitrogen export}

Nutrient export increased for each of the scenarios, indicating that urbanization generally results in poorer water quality. Annual phosphorus export had the greatest increase by maintaining the status quo, with an additional 17,588 kg (Fig. 4c). Both the infill and sprawl scenarios had increases in annual phosphorus exported but less than the status quo, with 17,370 and $16,454 \mathrm{~kg}$, respectively (Fig. 4c). The greatest increase in annual nitrogen export was from the infill and status quo scenarios with an additional 103,117 and 103,263 kg exported, respectively (Fig. 4d). The sprawl scenario had an increase in nitrogen export as well, with 89,465 additional kilograms exported annually (Fig. 4d). These results suggest that an urban configuration of sprawl mitigates nitrogen export substantially better than both the infill and status quo scenarios. When these results are combined together, urban sprawl is found to have the least damaging impact on water quality compared to the other two scenarios. 
Fig. 2 A sample sub-region of urban growth scenarios depicted to highlight (clockwise from top left) a the current urban prior to applying the growth scenarios, and three simulations of urban growth with different spatial configurations of growth, c sprawl, and d infill. Note that all three scenarios have approximately the same amount of land converted but in very different visual configurations that are less obvious from landscape perspectives b maintaining status quo
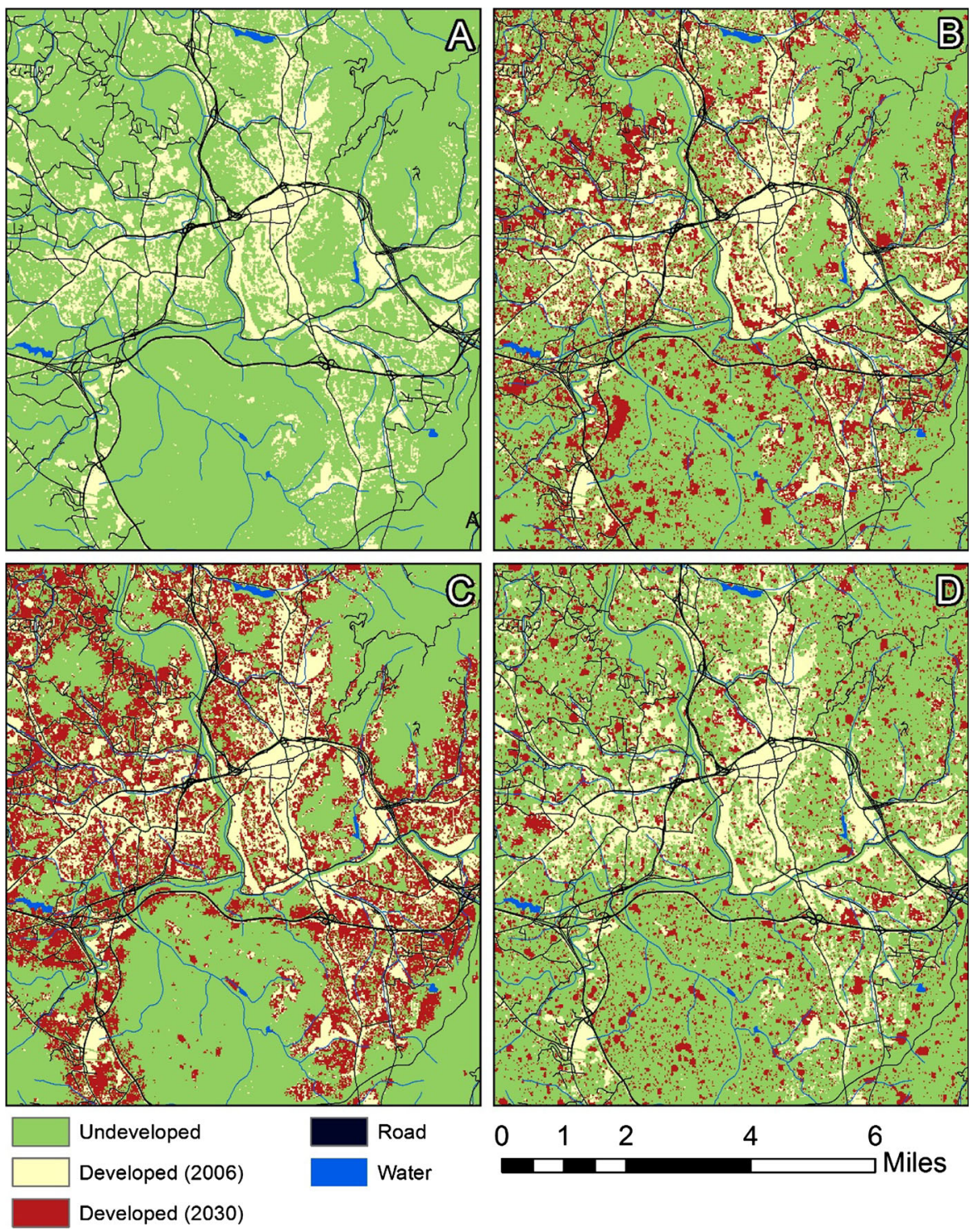

Fig. 3 Simulated infill and sprawl land cover percent change from 2005 to 2030 compared to the simulated status quo scenario. There was no change in barren land cover in the infill scenario compared to the status quo

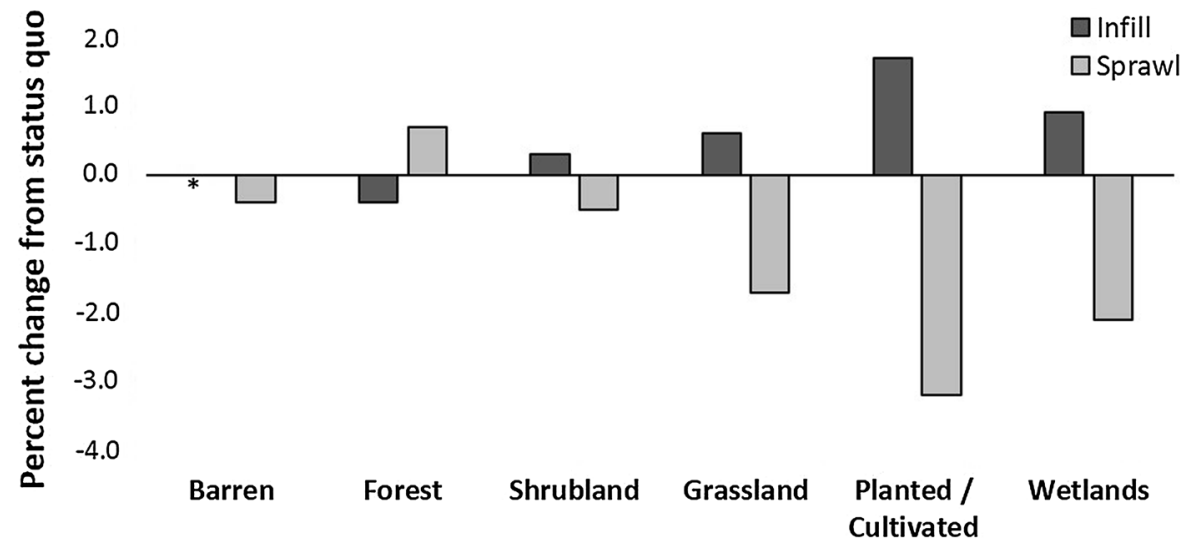


Fig. 4 Ecosystem service response in 2006 (dark grey) and 2030 (light grey) for: a carbon sequestration, b surface water run-off, c phosphorus export, d nitrogen export, $\mathbf{e}$ organic farming, and $\mathbf{f}$ camping site suitability for the three urban development scenarios
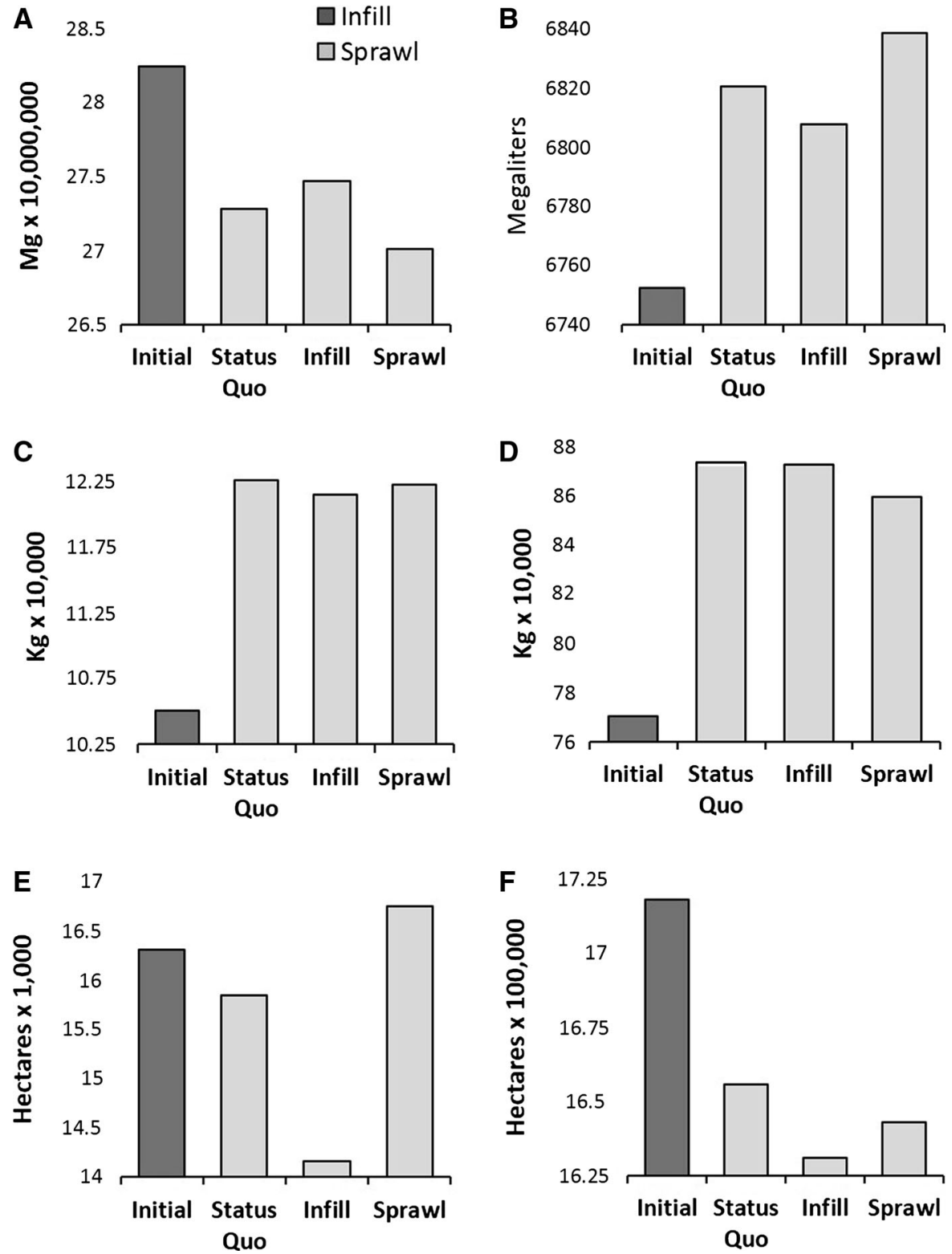

Potentially suitable organic farming lands

Modeled outputs of changes to potentially suitable organic farming lands demonstrated that urban configuration and the subsequent development of natural land cover will strongly impact the amount of lands available to organic farming (Fig. 4e). Under the status quo scenario approximately 46,755 ha of lands suitable for organic farming were lost due to urban expansion. We observed no change in the amount of lands available for organic farming using the sprawl scenario. Proximity to existing urban centers and distance to potable well water were significant predictor variables for highly suitable organic farming lands, therefore the sprawl scenarios placement of new urban away from existing urban allowed for all of the prime organic farming lands to be conserved. Within the generally mountainous terrain of the study region, the most suitable lands for organic farming occurs in the foothills and valley bottoms with moderate to no change in elevation. These locations are also areas where the probability of development is highest. The 
infill growth strategy caused a loss of 163,122 ha of the most suitable organic farming lands (Fig. 4e). This represents a $10 \%$ loss over the 25 years study period.

\section{Camping site suitability}

Urban expansion caused a decrease in the most suitable areas available for camping (Fig. 4f). This decrease was most pronounced in the sprawl and infill scenarios, with losses of 67,452 and 72,689 ha respectively (Fig. 4f). These results are consistent with the two most significant predictor variables of the model, travel time to large urban centers and forest cover. The status quo scenario preserved the most lands available for camping with a loss of 62,544 ha (Fig. 4f), suggesting that maintaining status quo growth could allow for more lands determined as being suitable for camping to be preserved better than either the sprawl of infill urban growth strategies.

\section{Discussion}

In this study we demonstrate the importance of understanding pattern, extent, and intensity of urban configuration for delivery of ES and the influence of context specific details of urban expansion associated with conversion of different land cover types. By considering scenarios that cover a broad range of possible urban growth patterns, we provide insight into how pattern can variably impact the delivery of ES. We found that ES loss varies significantly depending on the scenario, revealing trade-offs between growth strategies among the six ES (Fig. 5). Provision of four of six ES examined declined for the infill scenario as compared to the status quo, and three of six declined for the sprawl scenario. Four ES had both positive and negative responses (carbon sequestration, surface water runoff, nitrogen export and organic farming) under the infill and sprawl scenarios relative to the baseline status quo. The trade-offs we observed suggest that when it comes to increasing urbanization: no configurations result in mutual benefits to all ES (Fig. 5). These results are aligned with other studies evaluating trade-offs (Howe et al. 2014).

Previous study of the impacts of urbanization support our finding that pattern highly impacts ES delivery (Polasky et al. 2008; Beardsley et al. 2009; Nelson et al. 2009; Chaplin-Kramer et al. 2015), however, differences between findings highlight the often context specific nature of ES delivery. Examination of urban densification in the UK, for instance, showed that stream water quality and flood mitigation faired no worse with the use of a sprawl scenario compared to the status quo (Eigenbrod et al. 2011). Furthermore, losses of stored carbon and agricultural production were predicted to be three times greater with a sprawl scenario compared to a densification strategy (Eigenbrod et al. 2011). In the topographically complex environment of our study area, we found surface runoff to be greatest with the sprawl scenario in direct contrast with these results. The subsequent conversion of forest cover to impervious surface, with a high degree of surface and subsurface water uptake, combined with steeper sloped terrain can explain the increase in surface water runoff (Darby 1999). For carbon storage, our results are consistent with other studies (e.g. Eigenbrod et al. 2011), however we found that the potential for organic farming decreased with an infill scenario, directly conflicting with other studies projections of agricultural production. Again, this can be explained by the site specific modeling conducted within our study, as the most suitable lands for farming in the montane environment tended to be in valley bottoms and near rivers, locations also most suitable for urban development with the infill scenario. The different methods employed for assessing ES including the spatial resolution and indicators used, might likewise account for difference in results (Chan et al. 2006). Comparability between ES evaluation is a recurrent issue that still needs to be addressed in this emergent field (Schroter et al. 2014), especially as comparable studies for validation are often scarce.

In this study we only considered six ES, but the natural environment provides a multitude of benefits and trade-offs that should be evaluated when investigating the change resulting from urban expansion. Ecosystems surrounding an urban area provide many benefits, some of which may be difficult or impossible to quantify, that nonetheless provide substantial value to urban and rural populations. Previous research has predominantly focused on provisioning ES and largely missed modeling and mapping cultural ES (Howe et al. 2014). The six ES we evaluated were chosen to provide a more holistic perspective of how multiple ES, not just provisioning services, may be impacted from urban growth scenarios. As new technologies 
Fig. 5 Percent change of the six ecosystem services response based on the infill (dark gray) and sprawl (light gray) urban growth scenarios compared to the status quo

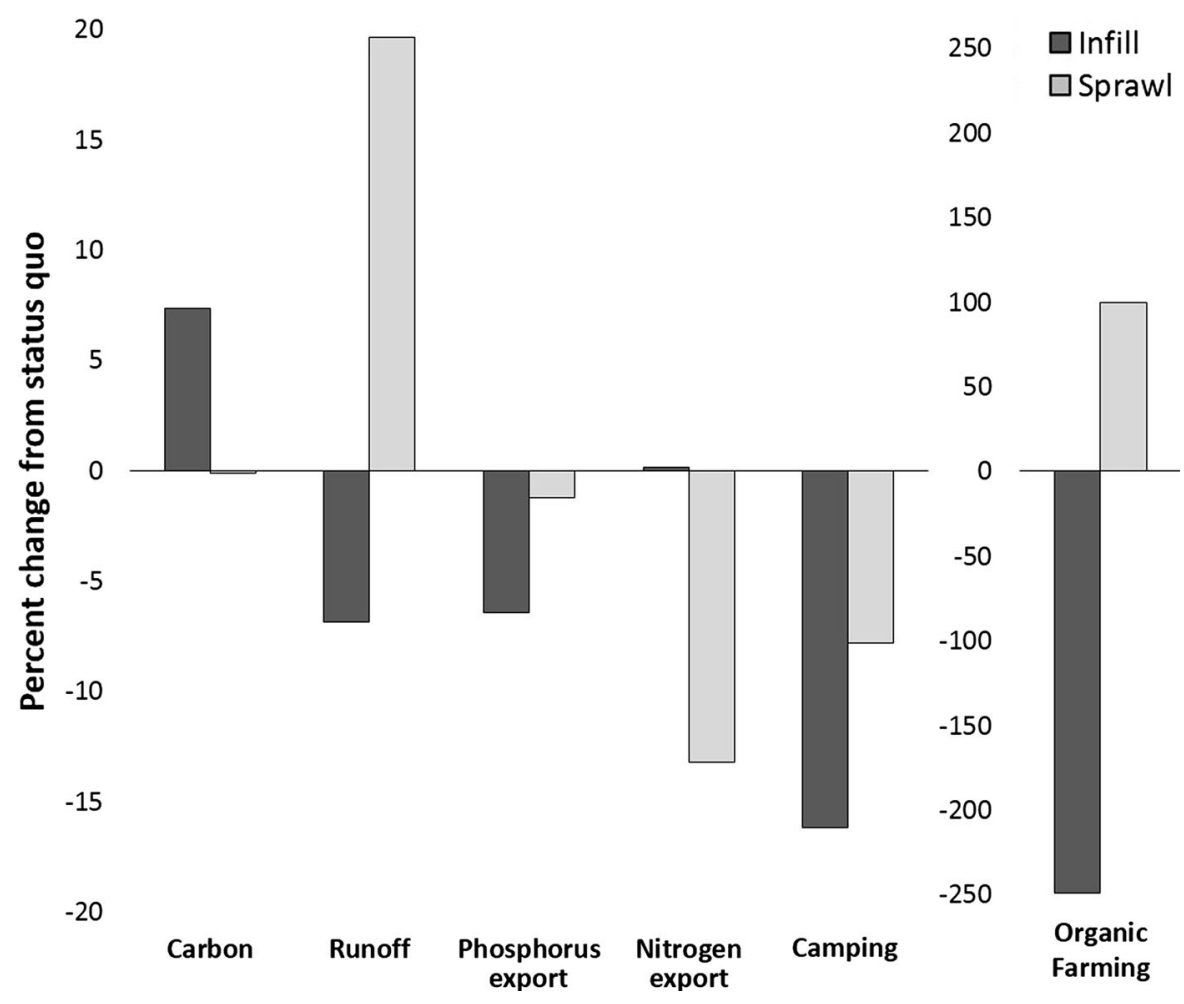

and data allow for modeling of these other ES, they should be included in spatial configuration studies, such as those described here, to fully understand the magnitude of impacts configuration can have on surrounding ecosystems (Chaplin-Kramer et al. 2015).

Urban ecological literature has predominantly focused on large urban centers where substantial expansion is expected to occur (e.g. Terando et al. 2014). Less understood are the impacts to ecosystem services in small urban centers with similar projected exurban development. As urban expansion continues throughout the US, both in large megaregions (Dewer and Epstein 2007) and in smaller communities' simultaneously, there exists a need to understand urbanization's impacts to ecosystem services across a spectrum of urban size and density. The work presented here aims to contribute to a growing body of research suggesting that trade-offs among ecosystem services differ when patterns of growth are realized for large urban centers when compared to smaller developments.

While ES evaluation was based on robust models and techniques that are commonly used, some limitations are important to consider when interpreting our results. The InVEST Nutrient Model, for instance, is limited to projecting annual average nutrient retention and export rates, and does not incorporate the inherent variability in climate related watershed characteristics. In addition, it only addresses filtration that occurs on the landscape surface through estimates of terrestrial vegetation and, therefore, does not model chemical or biological interactions (Sharp et al. 2015). While modeling surface and sub-surface interactions are essential in site-specific hydrological modeling, the InVEST nutrient model allows for changes in regional and sub-watershed scale landscape configuration to be estimated (Sharp et al. 2015). The InVEST Carbon Sequestration model evaluated carbon sequestered by land cover type only and did not model forest growth over the 25 years study period. Additionally, quantifying changes to total carbon sequestration from timber harvesting was not included, in part because harvest schedules are difficult to project due to economic uncertainties. Societal preference for camping and the landscape factors that contribute to organic farming could change in the future, resulting in highly different suitability for these ES. Our empirical analysis provides a snap shot of the landscape 
characteristics associated with these land uses. The landscape characteristics that are used are similar to studies examining landscape aesthetic (Howley 2011; Van Berkel and Verburg 2014) and organic farm suitability (Lerouge et al. 2016). Despite many of the ES model generalizations, we believe this approach demonstrates a critical first step towards predicting ES response to urban configuration.

The ES models that were used in this study are based on the assumption that different land covers supply ES ubiquitously. Future research should focus on enhancing the generalizability of assumptions incorporating the spatial specificity and the dynamics associated with the social and ecological drivers that shape ES. Modeling water-related ES could be improved by using fully distributed hydrologic models that allow for temporal dynamics at finer resolutions to be considered (e.g. Gebremariam et al. 2014). Our estimates of surface water run-off and nutrients exported, provide insights into regional trends, however they should not be evaluated in the context of sitespecific locations (e.g. an individual building sited adjacent to a stream). This study also assumed static climatic conditions, and chose not to consider how climate change may potentially impact these services. Studies are now suggesting that changing climate variables, such as increasing temperatures and changing precipitation regimes, may potentially overwhelm the importance of land use and land cover patterns (Bettez et al. 2015). While this is possible, we argue it is still critical to understand urbanizations impact. Future efforts should focus on combining urbanization and climate together to gain greater insights into sustainable development in the face of climate change.

When urban regions expand they do so in piecemeal fashion. In many contexts, especially in the US, urban growth occurs with some areas experiencing sprawl and other areas experiencing infill simultaneously. The FUTURES model is a sophisticated multi-level modeling framework that simulates these urban forms in a highly realistic manner and is calibrated using observed trends (Meentemeyer et al. 2013). When combined with the ES models, it allows for systematic isolation of ES response to a specific configuration of urban growth and the landcover types that are consumed as a result of that growth. The dynamics of land cover change are complex and intricately woven, however in order to fully understand land change it is imperative to first comprehend each dynamic component's response in relative isolation before simulating multiple changing configurations (e.g. urban growth and simultaneous farmland abandonment). Our methods present a technique for isolating how pattern influences ES delivery by controlling for total land change.

Our results can ultimately guide future urban growth policies and be used to prioritize urban configurations that promote services deemed necessary by stakeholders and communities. By understanding the trade-offs across urbanization scenarios, regional planning can identify specific ES that are most important to the area and promote urban configurations that enhance those ES. Local governments could apply policies, such as zoning restrictions, to constrict or promote specific development configurations for certain areas depending on the ES most desired. For example, communities concerned with water quality could use these methods to identify critical areas where urbanization may have the greatest detriment and constrict development to a specific configuration. Combining constricted development with systematic targeting of mitigation areas to restore previously degraded areas could potentially eliminate or reduce additional degradation from development. This type of site specific, targeted planning effort could allow for further development to maintain pace with projected population increases, while having the most benign impact to ES and the natural environment.

\section{Conclusion}

It is of critical importance to integrate this type of spatially explicit ES science into mainstream trade-off approaches. In the United States, universities, nongovernmental organizations, and federal agencies are actively collaborating to develop and apply ES concepts to further national environmental objectives (Schaefer et al. 2015). Therefore, the need to examine ES in the context of urbanization, both in terms of spatial configuration and changes observed through time, will be necessary to fully understand urbanization's impacts to national environmental objectives. It is reasonable to envision governments applying zoning restrictions that promote one urban configuration over another to address ES needs of a specific community (Bengston et al. 2004). Spatial 
configuration methodologies such as these may also allow for mitigation strategies to be developed in tandem with regional and localized zoning policies. Ultimately, considering the spatial configuration of urbanization can allow for anticipated increases in urban growth to occur in the most sustainable and resilient ways possible.

Acknowledgements The authors would like to thank John Vogler for data preprocessing and model development. This work was improved by the comments provided by Lindsey Smart and two anonymous reviewers. Ideas and concepts presented are solely those of the authors.

Open Access This article is distributed under the terms of the Creative Commons Attribution 4.0 International License (http:// creativecommons.org/licenses/by/4.0/), which permits unrestricted use, distribution, and reproduction in any medium, provided you give appropriate credit to the original author(s) and the source, provide a link to the Creative Commons license, and indicate if changes were made.

\section{References}

Beardsley K, Thorne JH, Roth NE, Gao S, McCoy MC (2009) Assessing the influence of rapid urban growth and regional policies on biological resources. Landsc Urban Plan 93:172-183

Belongie S, Malik J, Puzicha J (2002) Shape matching and object recognition using chape contexts. IEEE Trans Pattern Anal Mach Intell 24(4):509-522

Bengston DN, Fletcher JO, Nelson KC (2004) Public policies for managing urban growth and protecting open space: policy instruments and lessons learned in the United States. Landsc Urban Plan 69:271-286

Bettez ND, Duncan JM, Groffman PM, Band LE, O’Niel-Dunne J, Kaushal SS, Belt KT, Law N (2015) Climate variation overwhelms efforts to reduce nitrogen delivery to coast waters. Ecosystems 18:1319-1331

Blumstein M, Thompson JR (2015) Land-use impacts on the quantity and configuration of ecosystem service provisioning in Massachusetts, USA. J Appl Ecol 52:1009-1019

Carpenter S, Caraco N, Correll D, Howrath RW, Sharpley AN, Smith VH (1998) Nonpoint pollution of surface waters with phosphorus and nitrogen. Ecol Ind 8:559-568

Carruthers JI, Ulfarsson GF (2003) Urban sprawl and the cost of public services. Environ Plan 30:503-522

Chan KMA, Shaw MR, Cameron DR, Underowwd EC, Daily GC (2006) Conservation planning for ecosystem services. PLoS Biol 4:2138-2152

Chaplin-Kramer R, Sharp RP, Mandle L, Sim S, Johnson J, Butnar I, Canals LM, Eichelberger BA, Ramler I, Mueller C, McLachlan N, Yousefi A, King H, Kareiva PM (2015) Spatial patterns of agricultural expansion determine impacts on biodiversity and carbon storage. Proc Natl Acad Sci USA 112(24):7402-7407
Clark KC, Hoppen S, Gaydos L (1997) A self-modifying cellular automation model of historical urbanization in the San Francisco Bay area. Environ Plan 24:247-261

Costanza R, de Groot D, Sutton P, van der Ploeg S, Anderson SJ, Kubiszewski I, Farber S, Turner RK (2014) Changes in the global value of ecosystem services. Glob Environ Change 26:152-158

Daly C, Gibson WP, Doggett M, Smith J, Taylor G (2004) Upto-date monthly climate maps for the conterminous United States. In: 14th AMS conference on applied climatology, 84th AMS annual meeting combined preprints, 13-16 Jan 2004, Seattle, WA, Paper P5.1

Darby SE (1999) Effect of riparian vegetation on flow resistance and flood potential. J Hydraul Eng 125:443-454

De Groot RS, Alkemade R, Braat L, Hein L, Willemen L (2010) Challenges in integrating the concept of ecosystem services and values in landscape planning, management, and decision making. Ecol Complex 7:260-272

Dewer M, Epstein D (2007) Planning for "megaregions" in the United States. J Plan Lit 22:108-124

DiLuzio M, Johnson GL, Daly C, Eischeid JK, Arnold JG (2008) Constructing retrospective gridded daily precipitation and temperature datasets for the conterminous United States. J Appl Meteorol Climatol 28:2031-2064

Dorning MA, Kock J, Shoemaker DA, Meentemeyer RK (2015) Simulating urbanization scenarios reveals trade-offs between conservation planning strategies. Landsc Urban Plan 136:28-39

Downs A (1999) Some realities about sprawl and urban decline. Hous Policy Debate 10:955-974

Drinkwater LE, Wagoner P, Sarrantonio M (1998) Legumebased cropping systems have reduced carbon and nitrogen losses. Nature 396:262-265

Eigenbrod F, Bell VA, Davies HN, Heinemeyer A, Armsowrth $\mathrm{PR}$, Gaston $\mathrm{Kj}$ (2011) The impact of projected increases in urbanization on ecosystem services. Proc R Soc B 278:3201-3208

Fry JA, Xian G, Jin S, Dewitz JA, Homer CG, Yang L, Barnes CA, Herold ND, Wickham JD (2011) Completion of the 2006 national land cover database for the conterminous United States. Photogr Eng Remote Sens 77:858-864

Garcia AM, Hoos AB, Terziotti S (2009) A regional modeling framework of phosphorus sources and transport in streams of the southeastern United States. J Am Water Resour Assoc 47(5):991-1010

Gebremariam SY, Martin JF, DeMarchi C, Bosch NS, Confesor R, Ludsin SA (2014) A comprehensive approach to evaluating watershed models for predicting river flow regimes critical to downstream ecosystem services. Environ Model Softw 61:121-134

Gude PH, Hansen AJ, Jones DA (2007) Biodiversity consequences of alternative land use scenarios in greater Yellowstone. Ecol Appl 17(4):1004-1018

Hamidi S, Ewing R (2014) A longitudinal study of changes in urban sprawl between 2000 and 2010 in the United States. Landsc Urban Plan 128:72-82

Holcombe RG, Williams DW (2012) Urban sprawl and transportation externalities. Rev Reg Stud 40(3):257-272

Homer CG, Dewitz JA, Yang L, Jin S, Danielson P, Xian G, Coulston J, Herold ND, Wickham JD, Megown K (2015) Completion of the 2011 National Land Cover Database for 
the conterminous United States-representing a decade of land cover change information. Photogramm Eng Remote Sens 81(5):345-354

Hoos AB, McMahon G (2009) Spatial analysis of instream nitrogen loads and factors controlling nitrogen delivery to streams in the southeastern United States using spatially referenced regression on watershed attributes (SPARROW) and regional classification frameworks. Hydrol Process 23(16):2275-2294

Howe C, Suich H, Vira Bhaskar, Mace GM (2014) Creating win-wins from trade-offs? Ecosystem services for human well-being: a meta-analysis of ecosystem service trade-offs and synergies in the real world. Glob Environ Change 28:263-275

Howley P (2011) Landscape aesthetics: assessing the general publics' preferences towards rural landscapes. Ecol Front 72:161-169

Intergovernmental Panel on Climate Change (IPCC) (2006) IPCC guidelines for national greenhouse gas inventories, vol 4. Agriculture, Forestry and Other Land Use

Jaeger JA, Schwick C (2014) Improving the measurement of urban sprawl: weighted urban proliferation (WUP) and its application to Switzerland. Ecol Ind 38:294-308

Junge X, Lindemann-Mathies P, Hunziker M, Schupbach B (2011) Aesthetic preferences of non-farmers and farmers for different land-use types and proportions of ecological compensation areas in the Swiss lowlands. Biol Conserv 144(5):1430-1440

Kahn ME (2006) Green cities: urban growth and the environment. Brookings Institution Press, Washington, DC

Kaza N (2013) The changing urban landscape of the continental United States. Landscape and Urban Planning 110:74-86

Konrad CP, Booth DB (2005) Hydrologic changes in urban streams and their ecological significance. Am Fish Soc Symp 47:157-177

Laterra P, Orue ME, Booman CG (2012) Spatial complexity and ecosystem services in rural landscapes. Agric Ecosyst Environ 154:56-67

Lawler JJ, Lewis DJ, Nelson E, Plantinga AJ, Polasky S, Withey JC, Helmers DP, Martinuzzi S, Pennington D, Radeloff VC (2015) Projected land-use change impacts on ecosystem services in the United States. Proc Natl Acad Sci USA 111(20):7492-7497

Leopold LB (1968) Hydrology for urban land planning-a guidebook on the hydrologic effects of urban land uses. U.S. Geological Survey Circular 554, Washington, DC

Lerouge F, Sannen K, Gulinck H, Vranken L (2016) Revisiting production and ecosystem services on the farm scale for evaluating land use alternatives. Environ Sci Policy 57:50-59

Liu W, Zhang Q, Liu G (2012) Influences of watershed landscape composition and configuration on lake-water quality in the Yangtze River basin in China. Hydrol Process 26:570-578

Mader P, Fliessbach A, Dubois D, Gunst L, Fried P, Niggli U (2002) Soil fertility and biodiversity in organic farming. Science 296:1964-1967

Maskell LC, Crowe A, Dunbar MJ, Emmett B, Henrys P, Keith AM, Norton LR, Schoefield P, Clark DB, Simpson IC, Smart SM (2013) Exploring the ecological constraints to multiple ecosystem service delivery and biodiversity. J Appl Ecol 50(3):561-571

McDonald RI, Kareiva P, Forman RTT (2008) The implications of current and future urbanization for global protected areas and biodiversity conservation. Biol Conserv 141:1695-1703

Meentemeyer RK, Tang W, Dorning MA, Vogler JB, Cunniffe NJ, Shoemaker DA (2013) FUTURES: multilevel simulations of emerging urban-rural landscape structure using a stochastic patch-growing algorithm. Ann Assoc Am Geogr 103(4):785-807

Millennium Ecosystem Assessment (MEA) (2005) Ecosystems and human well-being: a framework for assessment. Island Press, Washington, DC

Nedkov S, Burkhard B (2012) Flood regulating ecosystem services-mapping supply and demand, in the Entropole municipality, Bulgaria. Ecol Ind 21:67-79

Nelson E, Mendoza G, Regetz J, Polasky S, Tallis H, Cameron R, Chan KM, Daily GC, Goldstein J, Kareiva PM, Lonsdorf E, Naidoo R, Ricketts TH, Shaw R (2009) Modeling multiple ecosystem services, biodiversity conservation, commodity production, and tradeoffs at landscape scales. Front Ecol Environ 7(1):4-11

North Carolina Division of Tourism (2014) The economic impact of travel on North Carolina counties. US Travel Association, Washington, DC

North Carolina Office of State Budget and Management (2012) State demographics branch. County/state population projections. North Carolina Office of State Budget and Management. www.obsm.state.nc.us/ncosbm/facts_and_ figures/socioeconomic_data/population_estimates

Pan Y, Birdsey RA, Fang J, Houghton R, Kauppi PE, Kurz WA, Phillips OL, Shvidenko A, Lewis SL, Canadell JG, Ciais P, Jackson RB, Pacala SW, McGuire AD, Piao S, Rautiainen A, Sitch S, Hayes D (2011) A large and persistent carbon sink in the world's forest. Science 333:988-993

Penman J, Gytarsky M, Hiraishi T, Krug T, Kruger D (2003) Good practice guidance for land use, land-use change and forestry. IPCC National Greenhouse Gas Inventories Programme and Institute for Global Environmental Strategies, Hayama

Petrasova A, Petras V, Van Berkel D, Harmon BA, Mitasova H, Meentemeyer RK (2016) Open source approach to urban growth simulation. Int Arch Photogramm Remote Sens Spat Inf Sci XLI-B7:953-959

Pimentel D, Harvey C, Resosudarmo P, Sinclair K, Kurz D, McNair M, Crist S, Shpritz L, Fitton L, Saffouri R, Blair R (1995) Environmental and economic costs of soil erosion and conservation benefits. Science 267:1117-1123

Polasky S, Nelson E, Camm J, Blair C, Fackler P, Lonsdorf E, Montgomery C, White D, Arthur J, Garber-Yontz B, Haight R, Kagan J, Starfield A, Tobalske C (2008) Where to put things? Spatial land management to sustain biodiversity and economic returns. Biol Conserv 141:1505-1524

Polasky S, Nelson E, Pennington D, Johnson KA (2011) The impact of land-use change on ecosystem services, biodiversity, and returns to landowners: a case study in the state of Minnesota. Environ Resour Econ 48:219-242

Pontius RG, Boersma W, Castella JC, Clarke K, Nijs T, Dietzel C, Duan Z, Fotsing E, Goldstein N, Kok K, Koomen E, 
Lippitt CD, McConnell W, Sood AM, Pijanowski B, Pithadia S, Sweeney S, Trung TN, Veldkamp AT, Verberg $P$ (2008) Comparing the input, output, and validation maps for several models of land change. Ann Reg Sci 42:11-37

Redhead JW, Stratford C, Sharps K, Jones L, Ziv G, Clarke D, Oliver TH, Bullock JM (2016) Empirical validation of the InVEST water yield ecosystem service model at a national scale. Sci Total Environ 570:1418-1426

Reganold JP, Glover JD, Andrews PK, Hinman HR (2001) Sustainability of three apple production systems. Nature 410:926-930

Renard D, Rhemtulla JM, Bennett EM (2015) Historical dynamics in ecosystem service bundles. Proc Natl Acad Sci USA 112(43):13411-13416

Ridd MK (1995) Exploring a V-I-S (vegetation-impervious surface-soil) model for urban ecosystem analysis through remote sensing: comparative anatomy for cities. Int $\mathbf{J}$ Remote Sens 16(12):2165-2185

Schaefer M, Goldman E, Bartuska AM, Sutton-Grier A, Lubchenco J (2015) Nature as capital: advancing and incorporating ecosystem services in United States federal policies and programs. Proc Natl Acad Sci USA 112(24):7383-7389

Schroter M, Zanden EH, Oudenhoven AP, Remme RP, SernaChavez HM, de Groot RS, Opdam P (2014) Ecosystem services as a contested concept: a synthesis of critique and counter-arguments. Conserv Lett 7(6):514-523

Seppelt R, Dormann CF, Eppink FV, Lautenback S, Schmidt S (2011) A quantitative review of ecosystem service studies: approaches, shortcomings and the road ahead. J Appl Ecol 48:630-636

Setto KC, Guneralp B, Hutyra LR (2012) Global forecasts of urban expansion to 2030 and direct impacts on biodiversity and carbon pools. Proc Natl Acad Sci USA 109(40):16083-16088

Sharp R, Tallis HT, Ricketts T, Guerry AD, Wood SA, ChaplinKramer R, Nelson E, Ennaanay D, Wolny S, Olwero N, Vigerstol K, Pennington D, Mendoza G, Aukema J, Foster J, Forrest J, Cameron D, Arkema K, Lonsdorf E, Kennedy C, Verutes G, Kim CK, Guannel G, Papenfus M, Toft J, Marsik M, Bernhardt J, Griffin R, Glowinski K, Chaumont N, Perelman A, Lacayo M, Mandle L, Hamel P (2015) InVEST Version 3.2.0 User's Guide. The Natural Capital Project, Stanford University, University of Minnesota, The Nature Conservancy, and World Wildlife Fund

SSURGO (2015) Soil Survey Staff, Natural Resources Conservation Service, United States Department of
Agriculture. Web Soil Survey. http://websoilsurvey.nrcs. usda.gov/. Accessed May 2015

Tayyebi A, Pijanowski BC, Pekin BK (2015) Land use legacies of the Ohio River Basin: using a spatially explicit land use change model to assess past and future impacts on aquatic resources. Appl Geogr 57:100-111

Terando AJ, Costanza J, Belyea C, Dunn RR, McKerrow A, Collazo JA (2014) The Southern Megalopolis: using the past to predict the future of urban sprawl in the Southeast US. PLoS ONE 9(7):1-8

Tuck SL, Winqvist C, Mota F, Ahnstrom J, Turnbull LA, Bengtsson J (2014) Land-use intensity and the effects of organic farming on biodiversity: a hierarchical metaanalysis. J Appl Ecol 51:746-755

United States Environmental Protection Agency (2001) Our built and natural environments: a technical review of the interactions between land use, transportation, and environmental policy. Report EPA 231-R-01-002. US Environmental Protection Agency. Washington, DC

United States Environmental Protection Agency (2014) Smart growth and economic success: investing in infill development. US Environmental Protection Agency, Washington, DC. https://www.epa.gov/sites/production/files/2014-06/ documents/developer-infill-paper-508b.pdf. Accessed July 2015

Van Berkel DB, Verburg PH (2014) Spatial quantification and valuation of cultural ecosystem services in an agricultural landscape. Ecol Ind 37:163-174

Verburg PH, Overmars K (2009) Combining top-down and botton-up dynamics in land use modeling: exploring the future of abandoned farmlands in Europe with the DynaCLUE model. Landscape Ecol 24(9):1167-1181

Verburg PH, Soepboer W, Veldkamp A, Limpiada R, Espaldon V, Mastura S (2002) Modeling the spatial dynamics of regional land use: the CLUE-S model. Environ Manag 30:391-405

Waddell P (2002) UrbanSim: modeling urban development for land use, transportation, and environmental planning. J Am Plan Assoc 68:297-314

Wu CS (2004) Normalized spectral mixture analysis for monitoring urban composition using ETM plus imagery. Remote Sens Environ 93(4):480-492

Ziter C (2015) The biodiversity-ecosystem service relationship in urban areas: a quantitative review. Oikos 00:01-08 